\title{
()ㅛㅇㅛ
}

\section{Modelagem Matemática e Tecnologias de Informação e Comunicação: a realidade do mundo cibernético como um vetor de virtualização}

\author{
Mathematical Modeling and Information and \\ Communication Technology: the reality of the \\ cyberworld as a vector of virtualization
}

\author{
Rodrigo Dalla Vecchia* \\ Marcus Vinicius Maltempi**
}

\begin{abstract}
Resumo
Neste artigo construímos um entrelaçamento teórico-filosófico que tem como objetivo discutir a relação entre Modelagem Matemática e realidade do mundo cibernético. Em particular, essa abrangência da realidade é evidenciada como um possível vetor de virtualização, isto é, como um aspecto que pode influenciar o modo como a problemática que envolve uma determinada situação ou entidade é compreendida. Para tanto, fazemos uma associação entre Modelagem Matemática e as transformações que envolvem os modos de ser denotados por real, possível, atual e virtual, tendo como base ilustrativa as quatro causas aristotélicas. Complementando essa associação, assumimos uma concepção de problema que permite uma consolidação entre as relações estabelecidas

"Doutorando do Programa de Pós-Graduação em Educação Matemática da Universidade Estadual Paulista (UNESP), campus de Rio Claro, SP, Brasil. Professor do Departamento de Matemática da Universidade Luterana do Brasil (ULBRA), Canoas, RS, Brasil. Membro do Grupo de Pesquisa em Informática, outras mídias e Educação Matemática (GPIMEM). Membro do Grupo de Pesquisa em Ambientes Matemáticos de Aprendizagem com Inclusão da Informática na Sociedade (AMAIIS). Endereço para Correspondência: Rua Coronel Sobral, 1404, Bairro Nossa Senhora Aparecida, CEP: 95960-000. Encantado, RS, Brasil.E-mail: rodrigovecchia@gmail.com.

*** Doutor em Engenharia Elétrica pela Universidade Estadual de Campinas (UNICAMP). Professor do Programa de Pós-Graduação em Educação Matemática da Universidade Estadual Paulista (UNESP), Campus de Rio Claro, SP, Brasil. Membro do Grupo de Pesquisa em Informática, outras mídias e Educação Matemática (GPIMEM). Endereço para Correspondência: Universidade Estadual Paulista, Departamento de Matemática (UNESP/DEMAC) Av. 24-A, 1515, Bairro Bela Vista, CEP 13506900, Rio Claro, SP, Brasil. E-mail: maltempi@rc.unesp.br
\end{abstract}


e, também, uma concepção de realidade que entende o mundo cibernético como uma de suas dimensões. Por fim, apresentamos um exemplo de Modelagem Matemática ocorrido em sala de aula, que visa caracterizar a realidade do mundo cibernético como um vetor de virtualização.

Palavras-Chave: Problema. Realidade. Virtual. Ensino de Matemática.

\begin{abstract}
In this paper, we build a theoretical-philosophical interlacing that aims to discuss the relationship between Mathematical Modeling and the reality of the cyberworld. This reality is particularly viewed as a possible vector of virtualization, i.e. as an element that enables the transformation of the perception of the problem involving a particular situation or entity. To do so, we make an association between mathematical modeling and transformations that involve the ways of being denoted by real, possible, current and virtual, through the four Aristotelian causes. Complementing this association, we assume a conception of problem that allows a consolidation among the established relationships and also a conception of reality that sees the cyberworld as one of its dimensions. Finally, we present an example of mathematical modeling from the classroom, aiming to characterize the reality of the cyberworld as a vector of virtualization.
\end{abstract}

Keywords: Problem. Reality. Virtual. Mathematics Education.

\title{
1 Introdução
}

O relacionamento da Modelagem Matemática com as Tecnologias de Informação e Comunicação (TIC) é uma linha de investigação que vem se consolidando dentro do campo da Educação Matemática. No cenário brasileiro, pesquisas como as de Diniz (2007), Araújo (2002), Borba, Malheiros, Zulatto (2007), Dalla Vecchia e Maltempi (2009; 2010) e Javaroni (2007) mostram potencialidades dessa relação. No âmbito internacional, essa linha também se confirma, representada por autores como Sinclair e Jackiw (2010), Chao, Empson e Shechtman (2010), Kazak (2010), Hills (2010) e Campbell (2010).

Em uma breve busca na literatura, o que se mostra é um quadro em que essa relação é íntima. Para reforçar essa colocação, e apresentar a problemática que envolve este artigo, recorremos à coletânea de textos divulgada no XIII ICTMA (International Conference on the Teaching of Mathematical Modeling and Applications), publicada por Lesh et al. (2010). Nesse livro, os autores procuraram reunir artigos em seções cujos títulos são dados por questionamentos. A seção 10 reúne as pesquisas que envolvem Modelagem 
Matemática e Tecnologia, sob o título How Do New Technologies Influence Modeling in School? Nela são apresentados cinco artigos que mostram, de modo geral, interações entre softwares e estudantes em situações que envolvem a Modelagem Matemática.

Nossa interpretação acerca das perguntas colocadas pelos organizadores é que as mesmas não apenas direcionam o rumo da leitura - no sentido de encontrar indícios de respostas ao questionamento proposto - mas, também, conduzem a uma reflexão sobre o encaminhamento das pesquisas, apontando, de forma implícita, os rumos e as questões abertas no campo de estudo da Modelagem Matemática. Particularizando para a seção 10 do referido livro, entendemos que o título nos mostra uma relação já consolidada entre Modelagem Matemática e tecnologias, e nos conduz a uma reflexão sobre a própria compreensão da Modelagem Matemática quando se faz presente o mundo criado com as TIC. Nesse sentido, nossa primeira interrogativa é: o que muda na Modelagem Matemática com o uso das TIC?

Ensaiamos uma resposta rápida a essa pergunta, recorrendo às palavras de Borba, Malheiros e Zulatto (2007, p.100), que afirmam que, com o advento das tecnologias "[...] diversas das atividades que hoje são apresentadas em sala de aula não serão mais problemas". Focamos nossa atenção à ideia que essa citação traz, de alteração na maneira como a situação pode ser conduzida pelos que nela se envolvem, sendo entendida como problema em um determinado contexto enquanto que, em outro, não. Levando essa perspectiva ao campo da Modelagem Matemática, podemos conjeturar que a entrada das TIC pode influenciar na problemática investigada, configurando mudanças no encaminhamento e na busca por soluções. Assumindo isso como premissa, apresentamos nossa segunda interrogativa, que decorre da primeira: quais aspectos influenciam nessa mudança no modo como o problema é entendido e de que forma influenciam?

$\mathrm{Na}$ literatura que embasa nossa investigação, os aspectos que proporcionam uma alteração no modo como a situação pode ser observada ou analisada são denominados vetores de virtualização (LÉVY, 1996). Procuramos, neste artigo, elaborar a ideia de que a realidade - em particular a realidade do mundo cibernético - pode ser vista como um vetor de virtualização, no sentido de afetar o modo como o problema que envolve a situação investigada está sendo conduzido por meio do processo de Modelagem Matemática.

Optamos pelo foco na realidade por dois motivos. O primeiro é sustentado nas pesquisas de Dalla Vecchia e Maltempi (2009; 2010) que, em uma revisão 
de literatura, mostram que, embora existam distintos modos de conceber a Modelagem Matemática, os termos realidade e problema parecem perpassar pelos mesmos. Anastacio (1990; 2010) e Araújo (2002; 2007) também atentam para este aspecto, mostrando a intrínseca relação entre Modelagem Matemática e realidade.

O segundo motivo está relacionado à influência das tecnologias digitais frente ao real. Com o advento dessas, a natureza delicada que envolve o real se potencializa, gerando adjetivações como: realidade do ciberespaço, realidade do mundo cibernético, realidade aumentada, hiperrealidade, realidade virtual, realidade mundana, realidade física etc. Assumindo que existe uma relação íntima entre Modelagem Matemática e realidade, mostrada por Dalla Vecchia e Maltempi (2009; 2010), Anastacio (1990; 2010) e Araújo (2002; 2007), cabe apresentarmos nosso terceiro questionamento: a realidade a que a Modelagem Matemática se refere abrange a realidade do mundo cibernético ${ }^{1}$ ? Em outras palavras, existem aportes teóricos que sustentam a realidade do mundo cibernético como uma dimensão da realidade?

Buscamos, neste artigo, contribuir para uma compreensão das interrogativas levantadas num campo teórico. Entendemos que apresentar o mundo cibernético como uma dimensão da realidade e como um vetor de virtualização, englobará parte das inquietações levantadas nessa introdução, oferecendo, ainda, suporte para compreender a relação entre Modelagem Matemática e tecnologias não apenas numa dimensão pragmática, mas, também, na teórica.

Para que essa construção seja desenvolvida, apresentamos, inicialmente, uma associação que permite simplificar nosso entendimento acerca dos processos que a Modelagem Matemática envolve, baseada em uma releitura das Quatro Causas Aristotélicas feitas por Lévy (1996). Como foco principal, será discutido o virtual. Em um segundo momento, para auxiliar no aprofundamento teórico, trazemos a concepção de Deleuze (1988) sobre problema, a qual se configura como um importante aspecto no entrelaçamento teórico que estamos construindo. Igualmente, nos valemos dos pressupostos de Bicudo (1999) e de Bicudo e Rosa (2010) para caracterização de uma visão de real que, além de acolher o mundo cibernético como realidade, mostra as especificidades e diferenças qualitativas que lhe conferem a adjetivação. Por último, relatamos exemplos da

\footnotetext{
${ }^{1}$ Usaremos o termo realidade do mundo cibernético para identificar um ambiente que abrange não somente o criado pela Internet, mas qualquer ambiente produzido pelas Tecnologias de Informação e Comunicação e tecnologias digitais.
} 
interação entre Modelagem Matemática e TIC que permitem identificar a realidade do mundo cibernético como um vetor de virtualização.

\section{As quatro causas aristotélicas e a modelagem matemática: analogias e ilustrações}

$\mathrm{Na}$ busca por um embasamento teórico que permitisse contribuir para uma visão de Modelagem Matemática que abarcasse o mundo cibernético sem se desprender de seus pressupostos básicos, encontramos aporte na ideia de virtual. Adotamos, neste artigo, uma postura filosófica que nos permite pensar no virtual como algo que vai além do modo de ver que o confunde com o espaço criado pelas tecnologias, e que o contrapõe ao real. Para tanto, nos baseamos em autores como Lévy (1996) e Deleuze (1988) que nos mostram que, para abranger a dinâmica que envolve um determinado fenômeno, é necessário compreender o relacionamento entre quatro aspectos ou formas na qual ele pode se mostrar, a saber, o virtual, o atual, o possível e o real. Conforme Lévy (1996), esses modos de ser são inerentes à situação particular investigada, estando entrelaçados de tal modo que sua separação não pode ser concebida, havendo, inclusive, uma constante transformação de um estado a outro, ocorrida na interação do fenômeno com o ser humano e as forças da natureza. Essas transformações são denotadas por virtualização, atualização, potencialização e realização.

Com o intuito de uma compreensão desses modos de ser, das transformações ocorridas entre eles e da relação que podem ter com o processo de Modelagem Matemática, apresentamos uma associação entre esses aspectos e as quatro causas aristotélicas. Para tanto, tivemos como base a analogia feita por Lévy (1996) entre as causas e as transformações ocorridas entre modos de ser atual, virtual, real e possível e a estendemos para o contexto da Modelagem Matemática.

De modo geral, a causalidade pode ser entendida como "[...] um nexo entre duas coisas em virtude do qual a segunda coisa é univocamente previsível a partir da primeira" (ABBAGNANO, 2007, p. 142). Aristóteles entende que buscar a relação entre duas coisas, ou se perguntar qual é a causa de algo, significa o mesmo que perguntar o porquê desse algo. Admitindo a existência de vários porquês, esse filósofo traz a perspectiva de considerar tipos distintos de causas. Sendo assim, considera, em suas ideias, quatro tipos de causas: causa material, causa formal, causa eficiente e causa final. 
Conforme Abbagnano (2007, p.142), a causa material pode ser considerada "[...] a causa daquilo que uma substância é feita e que permanece na coisa"; por exemplo, a causa material de uma cadeira pode ser a madeira; a causa formal está relacionada à forma ${ }^{2}$ ou à essência; a causa eficiente referese àquilo que inicia a mudança ou o repouso; e a causa final está relacionada diretamente à finalidade daquilo que se propõe a fazer ou analisar. Essas quatro causas, embora distintas, podem estar associadas a uma mesma situação ou objeto. Para ilustrar isso, Aristóteles associa as causas à construção de uma estátua de mármore. Nesse contexto, a causa material é designada pelo material utilizado, que é o mármore, a causa formal está no contorno da futura estátua, adormecida no mármore e no escultor, a causa eficiente consiste no agente da ação que é o escultor e, por último, temos a causa final que remete ao uso ou utilidade da estátua (LÉVY, 1996).

Para apresentar uma visão de Modelagem Matemática baseada nessa ilustração, no lugar da estátua colocamos a situação problemática a ser investigada, a qual envolve, de forma direta ou indireta, todos os aspectos expostos ao longo do artigo, e constitui o cerne de todo o processo. Associamos a causa material às mídias (oral, escrita, informática) e à linguagem matemática. É por meio dessa que se constrói o modelo (matemático) ou se justifica uma determinada tomada de decisão. É nos símbolos matemáticos e nas linguagens natural, científica e tecnológica que a Modelagem se realiza e se mostra, nutrindo uma forma pré-existente. A causa formal designa o conhecimento matemático, o conhecimento científico, o conhecimento empírico e o aparato tecnológico disponíveis, responsáveis pelos contornos, pela forma assumida. O acesso a esses conhecimentos e aparatos constitui o conjunto de possibilidades, dando, de maneira adormecida, forma ou estrutura à situação investigada.

A causa eficiente, colocamos em consonância com as pessoas que estão envolvidas na investigação da situação problemática (modelador, professor, alunos, investigador etc.). Nesse processo, é necessário desenvolver estratégias, interpretar, improvisar, resolver problemas, encaminhar situações, inventar uma forma a partir de uma configuração dinâmica de forças que dizem respeito às relações estabelecidas com o problema investigado. Por fim, temos a causa final, isto é, a finalidade, que envolve a busca do(s) por quê( $(s)$ ? e influencia o

\footnotetext{
${ }^{2}$ A filosofia aristotélica tem como uma de suas características a recusa da visão Platônica em distinguir o mundo das Formas, que é tido como sendo a verdadeira realidade, do mundo da experiência sensorial, considerado apenas uma aproximação imperfeita da realidade. Aristóteles entende que a forma ou a essência de um objeto empírico faz parte do próprio objeto, constituindo-o, assim como a matéria da qual é feito (KÖRNER, 1985; MACHADO, 1991).
} 
modo como o processo é conduzido e como o problema é compreendido, remetendo à busca de novos caminhos, novas configurações, novos problemas associados à problemática inicial.

Conforme já enunciado, nosso interesse em utilizar essa ilustração para caracterizarmos a Modelagem Matemática está na possibilidade de associá-la às quatro transformações que envolvem o virtual, o atual, o possível e o real. Nesse sentido, retornemos à primeira causa apresentada, a causa material. Essa, segundo Lévy (1996), está associada à realização, isto é, à passagem do possível ${ }^{3}$ para o real ${ }^{4}$. Já a causa formal pode ser associada ao movimento inverso da realização, que vai do real em direção ao possível e é identificada na literatura por potencialização.

O nome potencialização está diretamente relacionado à perspectiva física de entropia. Essa analogia é usada para identificar a dinâmica que envolve essas duas transformações. A realização dissipa “[...] irreversivelmente a energia utilizável ou os recursos disponíveis [...] [seguindo] a encosta do segundo princípio da termodinâmica, segundo o qual o crescimento da entropia num sistema fechado é inevitável" (LÉVY, 1996, p. 138). Já a potencialização produz ordem e informação, reconstituindo os recursos e reservas energéticos. A ela se associa um movimento capaz de inverter a lei da entropia crescente, como se ao colocar dois gases igualmente aquecidos separados por um pequeno orifício fosse possível, de um lado, colocar as moléculas com maior agitação e, do outro, as com menor, constituindo, assim, em dois recipientes, com temperaturas distintas (um quente e outro frio), ordenados segundo sua "agitação". Com esses argumentos Lévy (1996, p. 139) conclui:

O possível, ou diferença de potencial, é identicamente uma forma, uma estrutura ou uma reserva. Realização e potencialização pertencem ambas à ordem da seleção: escolha molar entre os possíveis, para a realização. Triagem molecular e reconstituição de uma forma, para potencialização.

\footnotetext{
${ }^{3}$ No escopo desse artigo o possível não pode ser confundido com o provável. Deleuze destaca o possível como remetendo à forma de identidade (de idêntico) do conceito: "[...] na medida em que o possível se propõe à "realização", ele próprio é concebido como a imagem daquilo que se assemelha" (DELEUZE, 1988, p. 340). Essa ideia também é compartilhada por Lévy (1996, p. 16), que afirma: "O possível é exatamente como o real: só lhe falta a existência". Assim, ao pensar no possível, devemos entendê-lo não como algo que pode ou não ser realizado (provável), mas como algo que basta o ato para se realizar.

${ }^{4}$ Embora num primeiro momento nossa concepção de real possa parecer associada unicamente ao material, assumimos, na seção seguinte, uma concepção de real e de realidade mais ampla e adequada para entrelaçar os elementos que tratamos aqui.
} 
De forma análoga à Lévy, vemos, também, um fluxo de transformações ao associarmos, no contexto da Modelagem Matemática, a causa material às mídias (oral, escrita e informática) e à linguagem matemática e a causa formal ao conhecimento matemático, científico, empírico e ao aparato tecnológico. Temos, de um lado, um conjunto de possíveis, dado pelo conhecimento existente, que nutre as situações investigadas de formas pré-existentes, constituindo uma espécie de reserva energética, e, de outro, o conjunto das mídias e da linguagem matemática, que dissipa essa "reserva energética", nutrindo essas formas préexistentes, revelando modelos e explicações dos fenômenos ou situações analisadas, por meio da matemática.

Apesar de compreendermos a relevância da dicotomia estabelecida pelas transformações realização e potencialização, no sentido de contemplarem a importante dinâmica entre conhecimento e sua representação em termos de mídia, ponderamos que existe uma incompletude, uma vez que ainda não foram considerados os agentes humanos nesse processo. Em nossa visão, o ser humano não se separa da realidade que vivencia, interpreta e percebe. Sendo assim, a dimensão humana é trazida e entrelaçada com a teoria assumida por meio das transformações que envolvem o virtual e o atual, denotadas por atualização e virtualização.

Assumimos, nesse artigo, o virtual como sendo "[...] um complexo problemático, o nó de tendências ou de forças que acompanha uma situação, um acontecimento, um objeto ou uma entidade qualquer" (LÉVY, 1996, p. 16). Assim, em termos filosóficos, o virtual não busca sua essência nas tecnologias, como comumente é considerado, mas, sim, na ideia de problema, encontrando sustentação num campo não atual.

Este complexo problemático, por meio das coerções que dizem respeito à especificidade da situação e das circunstâncias que encontrar, busca ou chama um processo de resolução, que é denotado dentro da escola filosófica que sustenta essa seção como sendo a atualização e consiste na passagem do virtual ao atual. Ao falar sobre atualização, Lévy (1996, p. 16) aponta que essa “[...] aparece então como a solução de um problema, uma solução que não estava previamente contida no enunciado. A atualização é criação, invenção de uma forma a partir da configuração das dinâmicas de forças e finalidades". Nesse contexto, o atual pode ser considerado um aspecto ou solução particular a um problema ou, em outras palavras, a maneira como a situação ou entidade se mostra ao observador no estado que contempla o aqui e o agora.

Em contrapartida à passagem do virtual ao atual, está a virtualização, 
que pode ser entendida como o movimento inverso da atualização, e vai do atual em direção ao virtual. É importante ressaltar que a virtualização não é a transformação de uma realidade em um conjunto de possíveis ou possibilidades ${ }^{5}$, mas sim um

[...] deslocamento do centro de gravidade ontológico do objeto considerado: em vez de se definir principalmente por sua atualidade (uma "solução"), a entidade passa a encontrar sua consistência essencial num campo problemático. (LÉVY, 1996, p. 17-18)

Assim, Lévy destaca que a virtualização influencia diretamente nas características fundamentais da entidade, situação ou objeto analisado, alterando a percepção que dele temos. Enquanto que a atualização parte de um problema ou complexo problemático, e vai em direção à solução, a virtualização parte da solução (do atual) para um problema. Cabe salientar que esse processo não diz respeito a um problema específico, mas, sim, a uma situação problemática que pode desencadear processos de atualizações distintos.

Com essa breve explanação, podemos retomar as causalidades. Se, num primeiro momento, vimos realização e potencialização como transformações associadas às causas material e formal, e que nos permitiram estabelecer associações entre conhecimento e aparatos tecnológicos e sua representação ou manipulação por meio das mídias, atentamos, agora, para as transformações atualização e virtualização e como essas se relacionam com as causas eficiente e final.

Associada à causa eficiente, temos a transformação denotada por atualização, que pode ser vista como uma solução que diz respeito ao complexo problemático que acompanha uma situação. A atualização “[...] não se contenta em reconstruir recursos, nem em colocar uma forma à disposição de um mecanismo de realização. Não: a atualização inventa uma forma. Ela cria uma informação radicalmente nova" (LÉVY, 1996, p. 139).

Por sua natureza, ela é associada à causalidade eficiente, uma vez que não se trata apenas de um simples movimento executante - esculpir, no caso ilustrado -, há a necessidade de interpretar, improvisar e resolver um problema.

\footnotetext{
${ }_{5}^{5}$ Ao analisar a estrutura do virtual, pode-se correr o risco de associar o virtual ao possível, ou ao conjunto de possibilidades. Porém, essa associação não apresenta uma avaliação rigorosa. Para Deleuze (1988) o possível é a oposição ao real; o processo do possível é a realização. Nesse sentido, Lévy (1996, p. 15) afirma que "O possível já está constituído, mas permanece no limbo. O possível se realizará sem que nada mude em sua determinação nem em sua natureza”.
} 
$\mathrm{Na}$ associação feita por nós com a Modelagem Matemática, colocamos essa causa em consonância com os envolvidos na investigação. Nesse contexto, o modelador, o professor, o aluno, o investigador etc., assumem um papel fundamental na busca por soluções ao problema analisado por meio do processo de Modelagem Matemática, utilizando o conjunto de conhecimentos que possuem, improvisando, buscando novos conhecimentos, criando estratégias de encaminhamentos, ou, em outras palavras, atualizando a situação problemática envolvida.

A causalidade final, por sua vez, está associada à virtualização, que trata da passagem do atual ao complexo problemático. Essa afinidade dá-se quando se entende que a busca por uma finalidade está diretamente relacionada à busca de um por quê? e à busca por uma compreensão ou reflexão acerca de toda a problemática que envolve uma dada situação, criando novos problemas e situações distintas das já analisadas.

Se retornarmos ao campo teórico, potencializamos essa postura de mudança no modo como a situação é compreendida ao assumirmos que o virtual está sempre contido no objeto ou situação, fazendo parte dele, ao mesmo tempo em que o constitui. Este caráter dialético de conformidade entre a natureza dos aspectos inerentes à entidade é evidenciado por Lévy (1996), que assume uma relação íntima entre a constituição da entidade e a produção de suas virtualidades: Por um lado, a entidade carrega e produz suas virtualidades: um acontecimento, por exemplo, reorganiza uma problemática anterior e é suscetível de receber interpretações variadas. Por outro lado, o virtual constitui a entidade: as virtualidades inerentes a um ser, sua problemática, o nó de tensões, de coerções e de projetos que o animam, as questões que o movem, são uma parte essencial de sua determinação. (LÉVY, 1996, p. 16, grifos do autor).

Temos, assim, uma dicotomia dada pelas transformações, envolvendo o par virtual/atual, que permite iniciar uma compreensão sobre a relação do humano e a dinâmica relacionada à investigação, por meio da matemática, de uma determinada situação. Em especial, a virtualização nos permite encaminhar a discussão para os aspectos que contribuem para que ocorra uma alteração no modo como a situação investigada pode ser compreendida, analisada ou observada. Como já enunciado na Introdução, esses aspectos constituem-se nos chamados vetores de virtualização que, em nossa visão, assumem uma 
posição de relevância ao possibilitarem que novas compreensões e encaminhamentos possam ser assumidos, podendo influenciar na construção de novos conhecimentos.

Para sintetizar os apontamentos levantados nessa seção, criamos o Quadro1.

\begin{tabular}{|l|l|l|l|}
\hline Transformação & $\begin{array}{l}\text { Caracterização da } \\
\text { transformação }\end{array}$ & Causalidade & Associação com a Modelagem Matemática \\
\hline Realização & $\begin{array}{l}\text { Eleição, queda de } \\
\text { potencial }\end{array}$ & Material & $\begin{array}{l}\text { A causa material está associada às mídias (oral, } \\
\text { escrita, informática) e à linguagem matemática. }\end{array}$ \\
\hline Potencialização & $\begin{array}{l}\text { Produção de } \\
\text { recursos }\end{array}$ & Formal & $\begin{array}{l}\text { A causa formal designa o conhecimento } \\
\text { matemático, o conhecimento empírico, e o aparato } \\
\text { tecnológico disponível. }\end{array}$ \\
\hline Atualização & $\begin{array}{l}\text { Encaminhamento de } \\
\text { problemas }\end{array}$ & Eficiente & $\begin{array}{l}\text { A causa eficiente está colocada em consonância } \\
\text { com as pessoas que estão envolvidas no processo } \\
\text { de investigação da situação problemática } \\
\text { (modelador, professor, alunos, investigador, etc.) }\end{array}$ \\
\hline Virtualização & $\begin{array}{l}\text { Invenção de } \\
\text { problemas }\end{array}$ & $\begin{array}{l}\text { A causa final envolve a busca do “por quê?”e as } \\
\text { transformações no modo como o problema é } \\
\text { compreendido. }\end{array}$ \\
\hline
\end{tabular}

Quadro 1 - Transformações e suas características.

Na visão de Lévy (1996), o real, o possível, o atual e o virtual são quatro modos de ser diferentes, mas que, dificilmente, operam de forma isolada em um determinado fenômeno ou situação que se queira analisar. Além disso, “[...] os processos de potencialização e de realização só adquirem sentido na dialética da atualização e da virtualização" (LÉVY, 1996, p. 142). De forma recíproca, os modos de realização e potencialização condicionam, de forma decisiva, a virtualização e a atualização. Sendo assim, temos a existência de duas dicotomias, a saber, real/possível e virtual/atual, que não se excluem, mas se complementam e se entrelaçam de maneira indissociável, ainda que possuam especificações particulares.

Todos esses aspectos estão subordinados ao modo como compreendemos uma determinada situação. Assim, é fatível pensar que, aquilo que é perceptível por uma pessoa em um dos quatro modos de ser apresentados, pode se mostrar em outro campo para outro observador. Trazendo ao contexto educacional, podemos exemplificar a situação levando em consideração as vivências dos professores e dos alunos. Enquanto que um conhecimento matemático pode estar no campo do possível para o professor diante de um dado experimento já vivenciado por ele, esse mesmo conhecimento pode se apresentar no campo virtual para o aluno que ainda não entrou em contato com o mesmo ou não reconhece a relação entre a situação envolvida e o contexto 
matemático já específico.

Sendo assim, e considerando o exposto nesta seção, compreendemos o processo de Modelagem Matemática não como algo estático e sequencial, mas, sim, como um desencadeamento fluido, sujeito às variações que implicam em constantes mudanças dos rumos seguidos e da forma como a situação problemática que envolve o fenômeno investigado é compreendida. Nesse sentido, acreditamos que o amparo filosófico nos proporcionou alento, não apenas para uma caracterização teórica dessa tendência da Educação Matemática, mas, também, para embasar uma postura didática frente à Modelagem Matemática, que permite visualizá-la como um processo que sempre está em transformação.

Numa perspectiva geral, a implicação dessa postura está diretamente relacionada à ideia de repensar constantemente a situação investigada como um problema inacabado, buscando não somente uma mudança na representação da situação por meio da matemática, mas, também, em uma transformação de toda problemática que envolve a entidade que está sendo analisada. Entendemos que a admissão dessa postura nos dá o primeiro passo para abordarmos uma visão de Modelagem frente às tecnologias.

Embora acreditamos ter iniciado essa relação, ainda resta esclarecer como as ideias, aqui discutidas, interagem com os pressupostos básicos da Modelagem Matemática. Esse aspecto é debatido na próxima seção, abrangendo aspectos teóricos que envolvem a concepção que assumimos de problema e de realidade.

\section{0 problema, a realidade e a realidade do mundo cibernético}

Nos argumentos que apresentamos até o momento, evidenciamos uma postura frente à Modelagem Matemática diretamente relacionada à ideia de repensar, constantemente, a situação investigada como um problema inacabado. Para tanto, associamos essa tendência às quatro causas aristotélicas, que permitiram que essa postura assumisse uma abordagem teórica, de modo a ensaiarmos um entrelaçamento entre a visão de Modelagem e o espaço criado pelas tecnologias. Contudo, para essa relação se dar de modo consonante, consideramos ser necessário discutir e assumir aspectos conceituais que se referem às concepções de problema e de realidade. Em particular, a discussão que envolve a realidade, abre o caminho para uma compreensão da realidade do mundo cibernético, consolidando o entrelaçamento desejado para esse artigo.

$\mathrm{O}$ aprofundamento no conceito de problema ocorre por dois motivos. $\mathrm{O}$ 
primeiro está relacionado à perspectiva de que, independente da concepção assumida, a Modelagem Matemática, de modo direto ou indireto, parece estar associada a uma situação problemática (DALLA VECCHIA; MALTEMPI, 2009; 2010). O segundo motivo diz respeito ao termo virtual que, como vimos, é entendido como sendo um complexo problemático (LÉVY, 1996) e, potencialmente, pode contribuir para uma compreensão do processo de Modelagem Matemática como algo em constante transformação, principalmente considerando a virtualização e os vetores de virtualização.

Na seção anterior, discutimos sobre a ideia de transformação do modo como o problema é compreendido, mas não questionamos se a sua natureza abarca uma característica dinâmica ou mutável. Ao fazermos um rápido levantamento histórico-filosófico, é possível encontrar distintas concepções de problema. De modo geral, tem-se, de um lado, a perspectiva de que o problema está diretamente relacionado com a proposição ou sentença que o representa (ABBAGNANO, 2007; DELEUZE, 1988). Nesse caso, a proposição é considerada o próprio problema ou, melhor dizendo, para os autores adeptos a essa visão "[...] os problemas e as proposições são em número igual ${ }^{\text {" }}$ " (DELEUZE, 1988, p. 258), havendo uma relação biunívoca entre os mesmos. Por outro lado, existem autores que defendem uma concepção de problema que não o coloca em biunivicidade com o modo como é representado, fazendo com que seja considerado anterior à proposição que o representa, refutando a associação entre problema e a pergunta ou à dúvida (ABBAGNANO, 2007). Aqui, assumimos uma noção baseada em Deleuze (1988), que se alinha com a segunda corrente filosófica apresentada ${ }^{7}$.

A dúvida pode ser entendida como "[...] um estado subjetivo de incerteza, ou seja, uma crença ou opinião não suficientemente determinada, ou a hesitação em escolher entre a asserção da afirmação e a asserção da negação" (ABBAGNANO, 2007, p. 348). Tendo sua base na incerteza, a dúvida já se constitui em uma espécie de vetor que aponta na direção de possíveis respostas. Entretanto, nem todo problema pode ser reduzido à dúvida. A natureza deles difere, no sentido de que o problema não é substituído pela resposta ou deixa de ocorrer quando é resolvido. Por exemplo, ao encontrar a vacina de uma doença,

\footnotetext{
${ }^{6}$ Essa não é a perspectiva defendida por Deleuze. Nessa citação apenas está fazendo uma explanação sobre outras correntes que divergem de seu pensamento.

${ }^{7}$ Lévy (1996) se baseou em Deleuze para construir suas ideias: "Na esteira de Gilles Deleuze, eu escrevi [...] que o real assemelha-se ao possível enquanto o atual responde ao virtual" (LÉVY, 1996, p. 137, destaque nosso). Dessa forma, temos que os apontamentos que envolveram o termo problema - inclusive a concepção de virtual, entendido como um complexo problemático - estão em consonância com a perspectiva que apresentamos.
} 
tem-se a possibilidade de solução para o problema. Porém, essa possibilidade não elimina o problema, uma vez que não garante que a doença não ocorrerá mais. Já a dúvida, “[...] uma vez resolvida, está eliminada e é substituída pela crença” (ABBAGNANO, 2007, p. 935).

Também, no conjunto de ideias que assumimos, o problema e a proposição que o representa mostram uma distinção de natureza. Nesse sentido, Deleuze (1988, p.258) afirma que os problemas são "extra-proposicionais". A analogia que fazemos para esclarecer essa afirmação é a mesma encontrada na relação entre uma paisagem, vista pelo pintor, e o quadro desenhado pelo mesmo. Assim como a tela pintada não é a situação vista, mas, sim, uma representação da mesma, a proposição não é o problema, mas uma forma de representá-lo. Nisso, devem ser levados em consideração os aspectos da linguagem usada para a representação, os aspectos que dizem respeito ao problema em si e o modo como o problema é visto pelos sujeitos que buscam sua determinação ${ }^{8}$.

A proposição, ou o modo como o problema é expresso, é considerada por autores como Deleuze (1988) como uma forma de conduzir o problema, já indicando possíveis respostas e o caminho pelo qual o problema vai se desvelar. Nesse sentido, assegura:

Por si mesma, uma proposição é particular e representa uma resposta determinada. Um conjunto de proposições pode distribuir-se de tal maneira que as respostas que elas representem formem os casos de uma solução geral (assim, os valores de uma equação algébrica). Mas, precisamente, gerais ou particulares, as proposições só encontram sentido no problema subjacente que as inspira. (DELEUZE, 1988, p. 265 , grifos do autor).

Com essa afirmação, Deleuze mostra uma visão de problema anterior à proposição que o representa. Porém, a noção de resposta que a proposição assume, está diretamente associada à ideia que esse filósofo traz de pergunta. De modo geral, aponta que não considera existir uma biunivocidade entre problemas e questões, mas ressalva a importância da pergunta como orientadora, como se fosse uma espécie de condutor na direção da solução. Em outras palavras, a pergunta

[...] exprime, portanto, a maneira pela qual um problema é desmembrado, cunhado, traído na experiência e pela

\footnotetext{
${ }^{8}$ A determinação é entendida, aqui, como uma forma de delimitar o(s) significado(s) que a situação carrega.
} 
consciência, de acordo com seus casos de solução apreendidos como diversos. Embora nos dê uma ideia insuficiente, ela nos inspira, assim, o pressentimento do que ela desmembra (DELEUZE, 1988, p. 257).

Esse papel que a pergunta e a proposição afirmativa assumem está, conforme Deleuze (1988), sempre atrelado ao quadro social de onde parte a inquietação, trazendo pontos de vista, considerando a experiência vivida e os possíveis interlocutores, levando em consideração as respostas passíveis de ser dadas. Desse modo, é possível observar a constituição de aspectos subjetivos e intersubjetivos na busca por proposições (afirmativas ou interrogativas) que representem o problema.

É importante, ainda, analisar a relação entre a determinação do problema e sua solução. Nesse sentido, Deleuze (1988, p. 267) afirma que um “[...] problema se determina ao mesmo tempo em que é resolvido; mas sua determinação não se confunde com a solução: os elementos diferem por natureza, e a determinação é como a gênese da solução concomitante". Com essa alegação, esse filósofo apresenta que, à medida que há uma imersão do sujeito ou dos sujeitos no problema, há uma busca por sua determinação, que pode ser entendida, grosso modo, como uma espécie de atualização do problema em termos de linguagem sob a forma de proposições (interrogativas, afirmativas, descritivas etc.). Entretanto, o modo como o problema é expresso já influencia e conduz a busca por soluções. É isso que o autor quer dizer com "o problema se determina ao mesmo tempo que é resolvido", isto é, a determinação do problema é o início, é a gênese que norteia a busca por uma solução. Mas essa determinação é apenas um caso particular do problema, podendo haver outras formas de interpretar e conceber a situação que está sendo investigada.

Nesse contexto, potencializa-se a ideia de que a proposição que representa um problema está carregada de um conjunto de suposições e coloca a percepção humana como um fator relevante no processo de determinação. Voltando nossa atenção para a relação entre problema e as perspectivas de atualização e virtualização, podemos ver uma subordinação das mesmas ao modo como o(s) sujeito(s) interpreta(m) a situação, fato que consolida a associação feita na seção anterior entre as causas eficiente e final e a entrada de agentes humanos no processo.

Assim, atribuímos ao problema uma natureza dinâmica e que comporta a ideia de mudança. Compreendendo que as situações problemáticas constituem 
um ponto fundamental da Modelagem Matemática, damos sustentabilidade à postura de percebê-la como um processo em transformação. Dessa forma, além da articulação com os aspectos apontados até o momento, temos que, ao não associar o problema com o modo como está sendo representado, não corremos o risco de engessar a estrutura investigativa, podendo, sempre, repensar a situação analisada como inacabada, buscando, assim, outras formas de compreendê-la, criando novas soluções e novos problemas.

Com relação à realidade, assumimos uma concepção que comungue com os apontamentos evidenciados até o momento e nos permita englobar a realidade do ciberespaço. Sendo assim, tomamos como referencial a perspectiva dada por Bicudo (1999, p. 31), que entende o real como

[...] um todo dinâmico, temporal, histórico, percebido no encontro homem-mundo, não separado daquele que o percebe, que dele fala e que o interpreta, construindo uma rede de significados na intersubjetividade, ao partilhar vivências e comunicar interpretações.

De modo geral, segundo Abbagnano (2007), a ideia de realidade sempre esteve relacionada a dois aspectos importantes: a existência da realidade (externa) e o modo de ser específico das coisas. Numa revisão rápida, podemos ver que parte dos esforços da filosofia se constituiu na busca de uma prova da existência da realidade. Porém, na visão exposta por Bicudo (1999) refuta-se a ideia de uma preocupação com a existência:

Crer na realidade do "mundo exterior" (com ou sem direito), demonstrar essa realidade (suficiente ou não), pressupor essa realidade (explicitamente ou não), tudo isso são tentativas que pressupõem antes de mais nada o sujeito sem mundo, vale dizer, não consciente de seu mundo, que deve, portanto, começar por fundar a segurança de seu mundo (ABBAGNANDO, 2007, p. 977).

Com essa visão, é possível eliminar a perspectiva da existência de um mundo exterior, abrindo um espaço de discussão que se preocupa com o modo de como as coisas do mundo se apresentam ao humano ou estão em relação a ele, focando uma perspectiva de sujeito com o mundo.

Assumindo essa concepção, colocamo-nos em consonância com a ideia de problema delineada aqui. De fato, ao compreender o dinamismo da realidade, não separando o mundo daquele que o percebe, damos à problemática relativa a 
qualquer fenômeno um caráter subjetivo, característico das vivências e conhecimentos de cada sujeito envolvido com a situação e intersubjetivo, dado pela presença de outros sujeitos e pelo compartilhamento de experiências entre sujeitos, que contribuem com outros pontos de vista, ampliando, assim, a compreensão daquilo que se investiga. Desse modo, toda inquietação está sujeita à percepção dos que a interpretam, podendo ser interpretada sob distintos olhares, assumindo distintas determinações dadas pelas proposições afirmativas ou interrogativas que a representam. Assim, não consideramos uma relação biunívoca entre o problema, que pode ser interpretado de diversas maneiras, e a proposição que busca sua determinação.

Entendemos que a concepção assumida neste artigo nos permite discutir a realidade nas suas adjetivações, em particular a realidade do mundo cibernético. Entretanto, é possível considerar esse mundo como uma das modalidades da realidade? Se, sim, quais os aspectos distintos que garantem a adjetivação e quais as possíveis consequências para a prática de Modelagem Matemática?

A concepção de realidade assumida a associa à percepção do humano, preocupando-se em como as coisas do mundo estão ou se relacionam para com o sujeito que as interpreta. Não há um mundo separado do humano, mas, sim, a ideia de ser-humano-com-o-mundo. Nesse contexto, o que se destaca é a dimensão do humano na espacialidade e temporalidade do campo das experiências vividas. Segundo Bicudo e Rosa (2010), essa essência não se perde ao falarmos da realidade do ciberespaço. Na busca por uma associação entre a concepção de realidade com o mundo cibernético, esses autores argumentam que esta última pode ser também compreendida como um modo de viver a vida na dimensão do humano. Para tanto, desenvolvem uma série de argumentos que a partir da compreensão da ciência, que tem como sustentação a matemática, como uma dimensão abrangida pela realidade. Sendo a matemática uma base também da informática, esses autores estendem seus argumentos à realidade do mundo cibernético, trazendo inquietações que dizem respeito às relações ocorridas nesse universo, por exemplo, o relacionamento entre pessoas.

Segundo eles, na realidade do ciberespaço, existem relacionamentos abordando diferentes modalidades, que podem abranger aquelas comuns ao humanamente vivido. Para concretizar tal afirmação, citam relações de afeto, comerciais, de troca de informações, de busca de pares para certos objetivos, como construções de conhecimento sobre um tema específico, jogos, de relações de ensino e de aprendizagem, de psicoterapia. Nesse sentido, complementam que tais relações, assim como na realidade mundana, "[...] conduzem a uma 
profunda percepção de si pela percepção do outro, visto como igual, encarnado, estando lá e eu aqui" (BICUDO; ROSA, 2010, p. 14). Com esses argumentos, se põem em consonância com sua visão de real, admitindo a realidade do ciberespaço não separada da dimensão do humano.

Mas, se este é o ponto de consonância, o que caracteriza a diferença, justificando a adjetivação? Para responder a esta pergunta, Bicudo e Rosa (2010) recorrem a dois aspectos importantes, que são tempo e espaço, que na realidade do mundo cibernético se mostram de forma distinta da realidade física clássica. Para eles, o espaço, caracterizado pelo onde, possui atributos específicos:

[...] o onde do mundo cibernético não cabe nesse espaço [espaço da física clássica], por diferentes razões. Não se trata de um espaço físico, que acolhe pontualmente pessoas e inter-relações, pois se expande por conexões que não se encaixam no gráfico cartesiano. São conexões velozes e que se bifurcam, criando outras conexões, atingindo outros espaços físicos, gerando múltiplas possibilidades de relações, configurando realidades possíveis, projetadas, inventadas (BICUDO; ROSA, 2010, p. 20).

Nesse espaço, a temporalidade também pode se mostrar distinta, gerando atualizações de problemáticas em tempos, velocidades e instantes que lhe são próprios e dizem respeito às situações vivenciadas pelo humano nesse ambiente. Com esses argumentos, os autores concluem: "A concepção que vai aos poucos se formando é que se trata sim de uma realidade na qual o espaço é visto como sendo diferente daquele a que se está acostumado no cotidiano" (BICUDO; ROSA, 2010, p. 20). Com isso, vemos que, de forma geral, a realidade do ciberespaço pode ser vista como abarcada pela realidade no sentido de vivida na dimensão do humano, e, o que a diferencia da realidade física, são as percepções de tempo e de espaço. Dessa forma, é possível encontrar um aporte teórico que sustenta respostas para algumas das inquietações levantadas no início do artigo acerca do entendimento da realidade do ciberespaço.

A relevância da busca por essa sustentação se dá ao assumirmos que, baseados em Dalla Vecchia e Maltempi (2010), juntamente com a perspectiva de problema, a concepção de realidade faz parte do conjunto de pressupostos básicos da Modelagem Matemática. Sendo assim, fizemos questão de, ao trazermos à discussão o universo criado pelas TIC, assumirmos uma perspectiva que nos permitisse compreender esse espaço como uma das dimensões da realidade. 
Além disso, a discussão levantada por Bicudo e Rosa (2010) nos mostra um modo de ver a natureza da realidade do mundo cibernético, que se diferencia nas noções de espaço/tempo. Sendo esses aspectos clássicos na lida da Modelagem Matemática, podemos nos questionar acerca da influência e potencialidade dos mesmos nessa tendência. Em particular, podem essas distinções qualitativas influenciar no modo como compreendemos um dado problema relacionado a alguma situação inquietante, fazendo com que a própria realidade do mundo cibernético possa ser vista como um vetor de virtualização? Para abordar esse questionamento, apresentamos uma atividade de modelagem trabalhada em sala de aula, na qual alguns aspectos específicos se mostraram preponderantes no encaminhamento das discussões do ambiente de Modelagem Matemática, para ilustrar algumas de nossas argumentações.

\section{0 problema da corda}

O problema da corda é trabalhado semestralmente na disciplina de Laboratório de Matemática Aplicada da Universidade Luterana do Brasil, com alunos do curso de Engenharia, conforme mencionado em Dalla Vecchia (2007). Consiste na proposta de modelagem do movimento de um ponto específico de uma corda que é balançada por dois alunos, criando um movimento constante de ondulação. Dessa situação, é possível abordar translações e rotações das funções trigonométricas básicas (seno e cosseno), bem como trabalhar com as noções de período. Além disso, a função resultante relata a posição do ponto fixado na corda em relação ao tempo, o que possibilita um aprofundamento nas ideias de velocidade e aceleração propiciadas por uma abordagem do ponto de vista do cálculo integral e diferencial.

A construção do modelo matemático não é baseada em etapas prédeterminadas e específicas. Para iniciar as atividades, apenas é mostrado o movimento que deve ser analisado. Os materiais utilizados ao longo do processo são uma corda de aproximadamente três metros, uma filmadora, uma régua e um computador que possui o software Windows Movie Maker, que possibilita a visualização de cada quadro com uma diferença de oito centésimos de segundo (0,08s).

Para este artigo, utilizamos os dados provenientes de uma turma do primeiro semestre do ano de 2009. Os alunos, reunidos em um único grupo, iniciaram o processo dinâmico encaminhado com a discussão acerca da necessidade de mensurar os dados que seriam coletados por meio da filmagem. 
Para tanto, decidiram construir, com o auxílio da fita métrica um conjunto de marcações, dispostas verticalmente com distanciamento constante de $10 \mathrm{~cm}$ entre uma e outra (Figura 1).

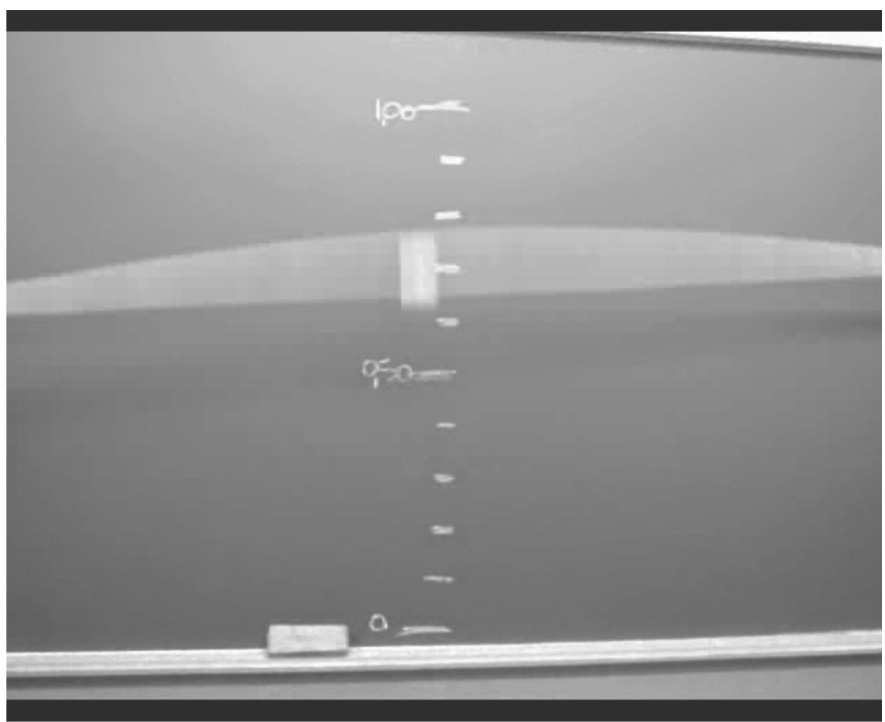

Figura 1- Experimento realizado em aula (amplitude).

Foram, assim, construídos 11 pequenos traços, sendo que ao primeiro, no sentido de baixo para cima, foi associado o valor 0 , ao sexto o valor 50 e ao último o valor 100, configurando 10 espaçamentos que abrangiam uma variação de 0 a 100.

Após esse início, os estudantes dedicaram-se à filmagem do balanço da corda. Por decisão coletiva, procuraram manter um movimento constante dentro da escala criada. Em seguida, os dados coletados foram compilados no computador. As oscilações filmadas costumam variar de 50 centésimos de segundo a um segundo. Dentre os vários ciclos filmados, escolheram um específico, com duração de 80 centésimos de segundo. O critério de escolha se deu pela adaptação do movimento da corda à escala de medidas criada. Da análise dos dados, obteve-se uma relação entre tempo e altura (posição) explicitada na Tabela 2. Com base nesses dados foi possível expressar essa relação por meio de um gráfico (Figura 2). 
Tabela 2 - Relação entre tempo e altura

\begin{tabular}{|c|c|}
\hline $\begin{array}{c}\text { Tempo } \\
\text { (segundos) }\end{array}$ & $\begin{array}{c}\text { Altura } \\
\text { (centímetros) }\end{array}$ \\
\hline 0 & 100 \\
\hline 0,08 & 85 \\
\hline 0,16 & 60 \\
\hline 0,24 & 25 \\
\hline 0,32 & 5 \\
\hline 0,40 & 0 \\
\hline 0,48 & 10 \\
\hline 0,56 & 32 \\
\hline 0,64 & 63 \\
\hline 0,72 & 90 \\
\hline 0,80 & 100 \\
\hline
\end{tabular}

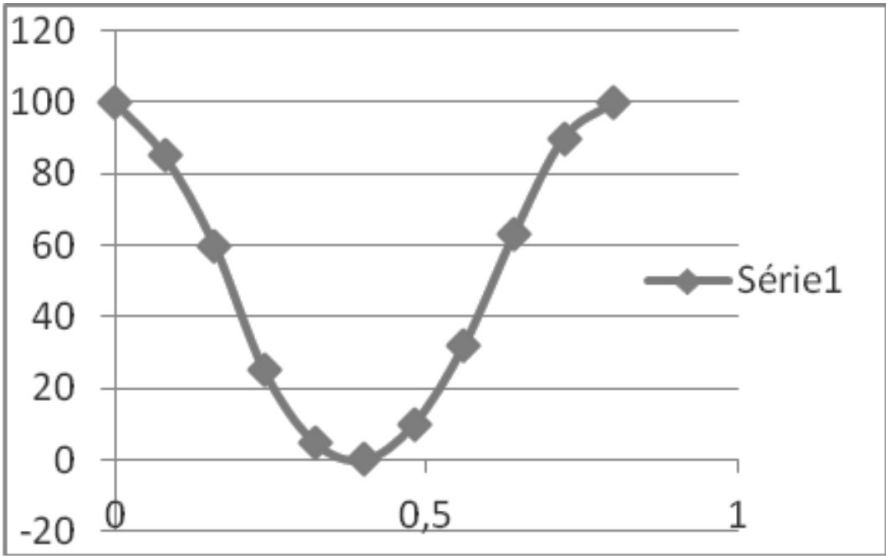

Figura 2 - gráfico da relação entre tempo e altura

A visualização do experimento no computador possibilitou a compilação dos dados e a construção de um gráfico que representasse a relação entre tempo e posição. Da análise gráfica, surgiram conjeturas a respeito do modelo que representasse essa relação. Por meio das ideias matemáticas que fazem parte das funções trigonométricas, foi possível determinar período, amplitude e deslocamento da função, de tal forma a construir o modelo $s=50+50 \cdot \cos \left(\frac{2 \pi}{0,8} \cdot t\right)$ (posição em cm). Usando o software Microsoft Excel, 
foi possível fazer um comparativo entre o modelo e a situação investigada (Figura $3)$.

Julgamos que, por meio desse exemplo, seja difícil apresentar toda a dinâmica abrangida pela alegoria criada que associa o processo de Modelagem Matemática às quatro causas aristotélicas. Para tanto, seria necessária uma gama de exemplos e detalhes que fogem ao escopo deste artigo. Mesmo assim, é possível, embora de maneira limitada, compreender que existe um entrelaçamento entre essas causas e os aspectos que envolvem o problema proposto.

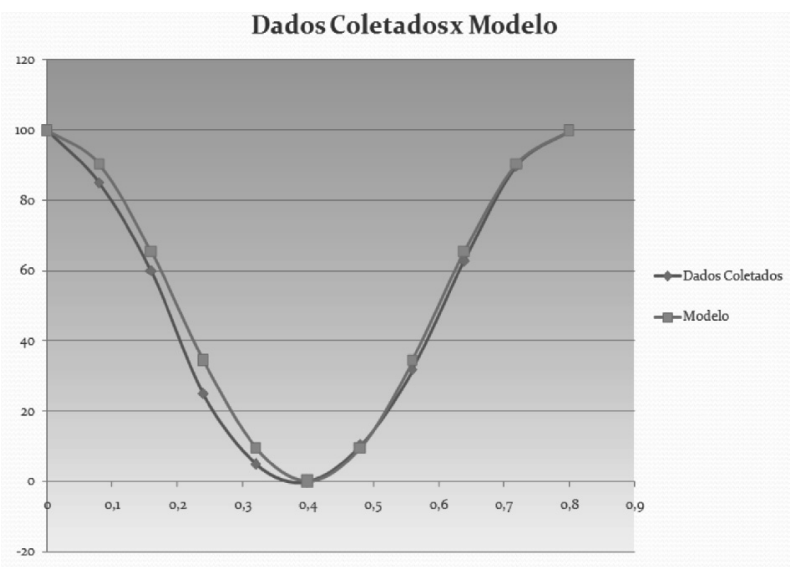

Figura 3 - comparativo entre situação investigada e modelo.

Se atentarmos inicialmente para o modelo em si, podemos ver as causas material e formal atuando em sua construção. Há, de um lado, um conjunto formado pelos conhecimentos que os envolvidos já possuíam (relações trigonométricas e associações entre suas componentes e o gráfico da função) e pelo aparato tecnológico disponível (filmadora e computador), que foram os recursos utilizados. Por meio desses, foi possível visualizar e coletar os dados, bem como construir um modelo matemático do movimento da corda observado. Assim, os recursos que ali estavam disponíveis e constituíam um campo possível (no sentido dado por Lévy (1996)), se realizaram, culminando com a construção

do modelo matemático dado pela expressão $s=50+50 \cdot \cos \left(\frac{2 \pi}{0,8} \cdot t\right)$.

Porém, essas transformações ocorridas entre um estado possível, gerado pelos recursos e a constituição de um modelo, não se mostraram agindo sozinhas, 
isoladas. Não há, em nosso entendimento, uma separação entre os acontecimentos e os envolvidos. Há todo um envolvimento das pessoas que criaram estratégias e utilizaram o conhecimento matemático e físico que haviam entrado em contato ao longo de sua trajetória, como estudantes, para buscar uma solução para a situação. Nesse sentido, houve um fluxo constante entre aquilo que já conheciam (um conjunto de formas pré-existentes) e os modos como o problema era expresso, tanto por meio de linguagem falada quanto pela simbologia matemática que, juntamente com os aspectos específicos do problema, nutriam esse conhecimento revelando explicações para a situação analisada. É nesse sentido que entendemos se manifestar a causa eficiente, associada por Lévy (1996) ao processo de atualização, isto é, ao encaminhamento dado ao problema, devido às circunstâncias encontradas.

Já a causa final recai sobre o próprio problema, que, neste caso em específico, entendemos ser a situação que se mostra aos estudantes. Do modo como é proposto, não há uma determinação específica, pronta ou acabada para o mesmo, mas, sim, uma situação que deve ser interpretada pelos alunos. A cada novo semestre letivo, há um novo resultado ou encaminhamento, havendo uma compreensão do problema, por parte dos alunos, que somente se mostra ao longo do próprio caminhar. É nesse sentido que interpretamos as ideias de Deleuze (1988, p. 267) quando diz que o "[...] problema se determina ao mesmo tempo em que é resolvido" (DELEUZE, 1988, p. 267). Embora no início do processo já houvesse uma série de conjeturas, o processo de Modelagem Matemática somente se definiu com a entrada do aparato tecnológico, pois somente por meio da precisão dada pelo computador foi possível observar um movimento contínuo em um intervalo de tempo de 80 centésimos de segundo.

Destacamos, ainda, que apesar do problema da corda ter uma referência em uma situação ocorrida na realidade mundana, todos os dados coletados puderam ser visualizados na realidade do mundo cibernético. Neste caso, ao observar a corda em um mundo diferenciado do físico, se fez presente, de maneira marcante, a característica tempo, ao possibilitar uma análise de cada instante capturado pela câmara, evidenciando, dessa forma, um tempo proporcionado somente pela realidade específica onde o problema foi analisado. Há, nesse caso, uma mudança nas características fundamentais do tempo de atualização da situação investigada, contribuindo para um "[...] deslocamento do centro de gravidade ontológico do objeto considerado" (LÉVY, 1996, p. 17-18), ou seja, em uma virtualização. Assim, o ocorrido pôde ser visualizado novamente, atualizado em outra realidade que comporta tempo e espaço distintos, 
transformando o modo como o problema pôde ser apreendido e compreendido, configurando o que Lévy (1996) denomina por vetor de virtualização.

Ao transpor a situação para o ciberespaço, as formas de visualização da entidade se alteraram, proporcionadas por uma leitura quadro a quadro (oito centésimos de segundo de precisão entre um quadro e outro), alterando a problemática e possibilitando uma leitura matemática mais precisa. O que enfatizamos, nesse instante, é a natureza da transformação da percepção do tempo: centésimos de segundo foram transformados em aspectos visualizáveis e analisáveis em outra dimensão de tempo, cabíveis em outra dimensão da realidade, a saber, a do mundo cibernético. É, justamente, nas potencialidades qualitativas desse onde, antevisto e entendido por Bicudo e Rosa (2010) como uma dimensão abrangida pela realidade, que focamos nossa atenção como pesquisadores, procurando compreender os modos como a Modelagem Matemática pode se mostrar frente às distinções que o mundo cibernético pode proporcionar.

\section{Conclusão}

Iniciamos o artigo mostrando que a interação entre Modelagem Matemática e TIC já acontece na prática didática e no campo investigativo da Educação Matemática. Sendo algo que está acontecendo e despertando o interesse de pesquisadores, nos questionamos: o que muda na Modelagem Matemática com a entrada das tecnologias digitais? Conjeturamos que a mudança se dá na problemática da situação envolvida e, com essa premissa, apresentamos nossa segunda interrogativa: Como e quais aspectos influenciam essa mudança no modo como o problema é compreendido? Chamamos esses aspectos que podem contribuir para uma mudança de perspectiva de vetores de virtualização. Pensando na possibilidade de existência de uma multiplicidade de vetores de virtualização, focamos nossa atenção na realidade - em especial na realidade do mundo cibernético - por entendermos que esse é um ponto central nas discussões que envolvem Modelagem Matemática. Sendo assim, partimos para um terceiro questionamento: Existem aportes teóricos que sustentam a realidade do mundo cibernético como sendo realidade?

Antes de iniciarmos a busca por respostas, apresentamos certas relações que visavam uma caracterização de Modelagem Matemática que sustentasse as discussões iniciadas pelas interrogativas. Procuramos, então, entrelaçar as perspectivas de real, possível, atual e virtual e suas transformações por meio da 
apresentação das quatro causas aristotélicas. Embora inicialmente buscássemos um embasamento que comportasse a ideia de realidade do ciberespaço ganhamos, no aprofundamento acerca do virtual, suporte filosófico para assumirmos uma postura teórica e didática frente à Modelagem, possibilitando-nos entendê-la como um processo que pode se mostrar em transformação.

O cerne dessa visão está em repensar constantemente a situação investigada como um problema inacabado, buscando não somente uma mudança na representação da situação por meio da matemática, mas, também, uma transformação no modo como a problemática que envolve a entidade está sendo analisada e compreendida. Enfatizamos, aqui, que isso pode não acontecer e que modificações nem sempre ocorrerão. A essência desses apontamentos não está na obrigatoriedade da mudança, mas, sim, na postura que permite pensar em uma multiplicidade de encaminhamentos e criação de novos problemas. Acreditamos que a virtualização e os vetores de virtualização assumem uma posição de relevância nesse contexto, ao possibilitarem que novos modos de compreensão da situação investigada possam ser assumidos, podendo vir a ser um aspecto importante não só no encaminhamento dos problemas, mas também na construção de novos conhecimentos.

Norteados por essa visão e pelos três questionamentos apontados na Introdução, buscamos referenciais teóricos que permitissem compreender a realidade criada pelas tecnologias como uma das dimensões da realidade e explicitar as características que lhe são inerentes. Baseados em Bicudo e Rosa (2010), pudemos acrescentar que a distinção está nas características inerentes à percepção de espaço e tempo. Com o enfoque nesses aspectos, procuramos observar uma situação envolvendo o uso de tecnologias e a Modelagem Matemática, apresentando as influências do espaço/tempo na construção de um modelo representativo de uma determinada situação, caracterizando a realidade do mundo cibernético no exemplo dado - o problema da corda - como um vetor de virtualização.

Cabe, nessa conclusão, acrescentar que deve haver um cuidado na leitura de compreender a realidade proporcionada pelo mundo cibernético como um vetor de virtualização. Não queremos confundir a simples presença de um software, de um computador, ou passagem de uma tecnologia à outra, com a virtualização. Tendo como base as ideias de Lévy (1996) e Deleuze (1988), há a necessidade de se criar um campo problemático, elevando a entidade ou situação analisada a este campo. Nesse constante processo, a tecnologia pode se tornar um dos vetores de virtualização. Voltando ao exemplo apresentado, 
observemos que o uso da tecnologia foi fundamental no ambiente de investigação instaurado, transformando centésimos de segundo em um tempo e espaço próprio da realidade do mundo cibernético, atualizado conforme nossa necessidade. Sendo assim, temos uma Modelagem Matemática que se potencializa por situações atualizadas de forma distinta da realidade mundana ou física.

Nosso interesse investigativo está, justamente, na potencialidade que esse espaço possui. Conforme Bicudo e Rosa (2010) a combinação das características inerentes ao espaço e ao tempo podem configurar um ambiente distinto do cotidiano, onde é fatível discutir uma perspectiva de realidade adjetivada, abrangendo realidades inventadas, projetadas e possíveis. Entendemos que a Modelagem Matemática, atrelada a esse contexto, pode assumir visões e perspectivas distintas, influenciando a maneira como determinadas situações são compreendidas e como a Matemática pode auxiliar nas discussões que envolvem esse espaço ou em como as situações desse espaço influenciam no processo de ensino e aprendizagem da matemática.

\section{Agradecimentos}

Agradecemos os seguintes pelas sugestões dadas durante a elaboração deste artigo: Claudinei de Camargo Sant'Ana, Daise Lago Pereira Souto, Débora da Silva Soares, Jhony Alexander Villa Ochoa, Marcelo de Carvalho Borba, Maurício Rosa e Silvana Claudia dos Santos.

\section{Referências}

ABBAGNANO, N. Dicionário de filosofia. São Paulo: Martins Fontes, 2007.

\section{ANASTACIO, M. Q. A. Realidade: uma aproximação através da modelagem}

matemática. Revista de Modelagem na Educação Matemática, Blumenau, v. 1, n. 1, p. 2-9, 2010 .

ANASTACIO, M. Q. A. Considerações sobre Modelagem Matemática e Educação Matemática. 1990. 104f. Dissertação (Mestrado em Educação Matemática) - Instituto de Geociências e Ciências Exatas, Universidade Estadual Paulista, Rio Claro, 1990.

ARAÚJO, J. L. Cálculo, tecnologias e modelagem matemática: as discussões dos alunos. 2002. 174f. Tese (Doutorado em Educação Matemática) - Instituto de Geociências e Ciências Exatas, Universidade Estadual Paulista, Rio Claro, 2002. 
ARAÚJO, J. L. Relação entre Matemática e Realidade em algumas Perspectivas de Modelagem Matemática na Educação Matemática. In: BARBOSA, J. C.; CALDEIRA, A. D.; ARAÚJO, J. L. (Orgs.). Modelagem Matemática na Educação Matemática Brasileira: pesquisas e práticas educacionais. Recife: SBEM, 2007, p. 17-32.

BICUDO, M. A. V. (Org.). Pesquisa em Educação Matemática: Concepções \& Perspectivas. São Paulo: Editora Unesp, 1999.

BICUDO, M. A. V.; ROSA, M. Realidade e Cibermundo: horizontes filosóficos e educacionais antevistos. Canoas: Editora da ULBRA, 2010.

BORBA, M. C.; MALHEIROS, A. P. S.; ZULATTO, R. B. Educação a Distância online . Belo Horizonte: Autêntica, 2007.

CAMPBELL, S. R. Mathematical Modeling and Virtual Environments. In: LESH, R.; GALBRAITH, P.; HAINES, C. R.; HURFORD, A. (Orgs.). Modeling Students'

Mathematical Modeling Competences. New York, U.S.A.: Springer, 2010. p. 583-596.

CHAO, T.; EMPSON, S. B.; SHECHTMAN, N. A principal Components Model of Simcalc Mathworlds. In: LESH, R. et al. (Orgs.). Modeling Students' Mathematical Modeling Competences. New York, U.S.A.: Springer, 2010, p. 555-560.

DALLA VECCHIA, R. Modelagem Matemática com o Auxílio de Tecnologias Informáticas. In: CONGRESSO INTERNACIONAL DO ENSINO DA MATEMÁTICA, 4., 2007, Canoas, RS. Anais... Canoas: Editora da ULBRA, 2007, p. 1-7. 1 CD-ROM.

DALLA VECCHIA, R.; MALTEMPI, M. V. Ensaio Sobre a Modelagem Matemática e o Virtual. In: ENCONTRO BRASILEIRO DE ESTUDANTES DE PÓS-GRADUAÇÃOEM EDUCAÇÃO MATEMÁTICA, 13., 2009, Goiânia. Anais... Goiânia: Universidade Federal de Goiás, 2009, p 1- 15. 1 CD-ROM.

DALLA VECCHIA, R.; MALTEMPI, M. V. Tecnologias Digitais e Percepção da Realidade: Contribuições para a Modelagem Matemática. In: ENCONTRO NACIONAL DE EDUCAÇÃO MATEMÁTICA, 10., 2010, Salvador. Anais... Salvador: Via Litteratum, 2010, p 1- 10.1 CD-ROM.

DELEUZE, G. Diferença e Repetição. Traduzido por: Luiz Orlandi; Roberto Machado. Tradução de: Différence et Répétition. Rio de janeiro: Graal, 1988.

DINIZ, L. N. O Papel das Tecnologias da Informação e Comunicação nos Projetos de Modelagem Matemática. 2007. 118f. Dissertação (Mestrado em Educação Matemática) - Instituto de Geociências e Ciências Exatas, Universidade Estadual Paulista, Rio Claro, 2007. 
HILLS, T. Investigating Mathematical Search Behavior Using Network Analysis. In: LESH, R. et al. (Orgs.). Modeling Students'Mathematical Modeling Competences. New York, U.S.A.: Springer, 2010, p. 571-582.

JAVARONI, S. L. Abordagem geométrica: possibilidades para o ensino e aprendizagem de Introdução às Equações Diferenciais Ordinárias. 2007. 231f. Tese (Doutorado em Educação Matemática) - Instituto de Geociências e Ciências Exatas, Universidade Estadual Paulista, Rio Claro, 2007.

KAZAK, S. Modeling Random Binomial Rabbit Hops. In: LESH, R. et al. (Orgs.). Modeling Students' Mathematical Modeling Competences. New York, U.S.A.: Springer, 2010, p. 561-570.

KÖRNER, S. Uma introdução à Filosofia da Matemática. Rio de Janeiro: Zahar, 1985.

LESH, R. et al. (Orgs.). Modeling Students' Mathematical Modeling Competences. New York, U.S.A.: Springer, 2010, p. 1-651.

LÉVY, P. O que é o virtual. São Paulo: Editora 34, 1996.

MACHADO, N. J. Matemática e Realidade. 3. ed. São Paulo: Cortez e Editores Associados, 1991.

SINCLAIR, N.; JACKIW, N. Modeling Practicies with The Geometer's Sketchpad. In: LESH, R. et al. (Orgs.). Modeling Students' Mathematical Modeling Competences. New York, U.S.A.: Springer, 2010, p. 541-554.

Submetido em Outubro de 2010. Aprovado em Janeiro de 2012. 